\title{
Research Paper: The Relationship Between Core Endurance and Performance in National Female Badminton Athletes
}

\author{
Hemn Mohammadi $^{1^{*}}$ (D), Jalil Fathi ${ }^{2}$ (D)
}

1. Department of Physical Education and Sport Sciences, Faculty of Humanity Sciences, University of Kurdistan, Sanandaj, Iran.

2. Department of English Literature \& Linguistics, Faculty of Literature and Foreign Languages, University of Kurdistan, Sanandaj, Iran.

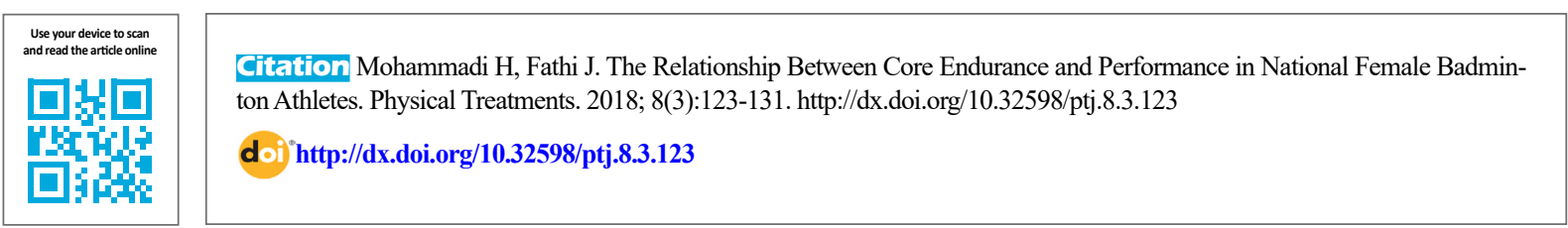

\section{(c) (1) (8)}

Article info:

Received: 10 May 2018

Accepted: 25 Aug 2018

Available Online: 01 Oct 2018

Keywords:

Badminton, Core endurance, Postural control, Physical performance

\begin{abstract}
A B S T RA C T
Purpose: A theory states that strong core stability allows athletes to fully transfer forces from the upper extremities to lower extremities, and finally to the ground. On the contrary, weak core stability causes alterations in transferring forces, reduces sport performance, and increases risk for injury, especially in the lower extremities. Therefore, the current study investigated the relationship between core endurance and performance in professional female badminton athletes.

Methods: To examine the aforementioned relationship, badminton athletes invited to the 2017 Youth National Team camp $(\mathrm{n}=16, \mathrm{Mean} \pm \mathrm{SD}$ age $=14.9 \pm 1.2 \mathrm{y}$, height $=163.0 \pm 4.5 \mathrm{~cm}$, weight $=57.8 \pm 4.3 \mathrm{~kg}$ ) completed core endurance and performance tests. Badminton athletes performed 5 performance tests ( $Y$ balance, vertical jump, $20 \mathrm{~m}$ sprint, $4 \times 9$ agility, and single-leg triple crossover hop tests), and 4 core endurance tests (trunk flexor, trunk extensor, and bilateral side bridge tests).

Results: Data analysis indicated significant correlations between core endurance and balance $(\mathrm{r}=0.52, \mathrm{P}=0.04)$, as well as between core endurance and triple crossover hop test $(\mathrm{r}=0.63$, $\mathrm{P}=0.01$ ); however, relations between core endurance and other performance tests (vertical jump, $20 \mathrm{~m}$ sprint, agility) were not statistically significant.

Conclusion: Considering the significant correlations between core endurance and balance and triple crossover hop test, it is suggested that personal trainers, coaches, and badminton athletes use the core stability exercises to improve balance and single-leg cutting maneuver. As a result, the chance of non-contact lower extremity injuries caused by the loss of balance or those occurring during cutting movement will be reduced.
\end{abstract}

\footnotetext{
* Corresponding Author:

Hemn Mohammadi, PhD.

Address: Department of Physical Education and Sport Sciences, Faculty of Humanity Sciences, University of Kurdistan, Sanandaj. Iran.

Phone: +98 (913) 6240282

E-mail: hemn.m.64@gmail.com
} 


\section{Highlights}

- There was a significant correlation between core endurance and balance in professional female badminton players.

- A significant correlation also existed between core endurance and athletic performance such as triple crossover hop test.

\section{Plain Language Summary}

The purpose of this study was to examine the relationship between core endurance and athletic performance in professional female badminton players. The results revealed significant correlations between core endurance and balance, as well as between core endurance and triple crossover hop test. Nevertheless, no significant relations were found between core endurance and other performance tests. The implications of this study might suggest that personal trainers, coaches, and badminton athletes employ the core stability exercises to enhance balance and physical performance.

\section{Introduction}

$\mathrm{t}$ is estimated that the participation rate I in badminton has increased by $22 \%$ from 2006 to 2016 [1]. Modern adaptations of the traditional rules, like reduction in badminton court sizes, and other factors such as jumps, lunges and unanticipated changes of direction and acceleration have turned badminton to a fast-paced sport maneuvering from midcourt to both court sides, forward, and backward to execute shots. These moves make the ankles, knees, and hip joints of badminton athletes go through flexed and extended positions $[1,2]$. Badminton is performed on a hard surface; therefore, athlete's joints may be subject to high ground reaction forces [2]. During a single-leg landing, knee valgus moment increases in badminton athletes with weak trunk flexion and these conditions predispose them to ACL injury [3]. For these reasons, $63.1 \%$ of injuries occur in the lower extremities (especially the knee [37.1\%] and ankle [28.3\%]) in badminton [1].

Badminton requires good balance and agility; the relationship between agility and performance during a badminton game is $\mathrm{r}=0.83$ [4]. Approximately $50 \%$ of injuries in badminton have occurred in females from 2001 to 2016 [1]. Players aged 5 to 18 years comprised the largest age group (58\%) and most injuries (40\%) occurred in schools/public properties. Strains/sprains were the most frequent sustained injuries (45\%). Injuries most prevalently occurred in the trunk (56\%) and lower extremity $(69 \%)$ [1]. Badminton players aged 5 to 18 years had a higher risk of fractures and lacerations, than those of any other age groups [1]. The turning (34.4\%), followed by general movements $(22.5 \%)$ were the most common mechanisms of badminton injuries, compared to lunging $(10.9 \%)$ or landing from jumps $(7.3 \%)$ [5]

Core muscle endurance and stability have attracted much attention within the last 3 decades in respect of sports injuries prevention, as fitness and sports training. The scientific foundation of traditional core stability exercise has recently been questioned, particularly in sports performance. A strong core zone enables an athlete to completely transfer ground reaction forces from the lower extremities to the torso, and ultimately to the upper extremities. Weak core zone reduces sports performance and increases risk for injury. Increased core strength and endurance may improve sports performance $[6,7]$.

Many studies have investigated the effect of core stability exercises on performance in different sports. Tse et al. argued that an 8-week core stability training program resulted in no significant changes in any performance tests among college-age rowers [8]. Stanton et al. also demonstrated that core stability exercises do not significantly improve physical performance in high school football and basketball athletes [9]. Additionally, the results of core stability exercises on high school-aged swimmers' performance indicated that their core strength significantly increased, but their performance did not significantly change [10].

Similarly, Ozmen and Aydogmus revealed that core strength training contributed to significant improvements in dynamic balance and agility among adolescent badminton athletes [11]. It seems that in many sports, such as football and basketball [9], swimming [10], and rowing [8], core stability exercises have no significant effect on athletic performance; however, in sports like 
badminton, core stability exercises can significantly improve athletic performance [11]. Therefore, there seems to be a significant relationship between performance and core stability in badminton, and this was the main hypothesis of the present study. Data are conflicting about the relationship between performance and core stability. Although Nesser et al. demonstrated no relationship between football athlete performance and core stability in national collegiate athletes [12], Sharrock et al. suggested a significant correlation between the core stability and performance [13].

Few studies have investigated the role of core endurance in performance among professional female athletes, although numerous studies have investigated the importance of core stability $[14,15]$. Therefore, the present study investigated the relationship between core endurance and various performances among high school female badminton athletes.

\section{Materials and Methods}

Sixteen national youth badminton team athletes (2017) $($ Mean \pm SD age $=14.9 \pm 1.2 \mathrm{y}$, height $=163.00 \pm 4.5 \mathrm{~cm}$, weight $=57.8 \pm 4.3 \mathrm{~kg}$ ) were tested at the central lab of Physical Education and Sports Sciences in Shahrood University of Technology. Table 1 presents the obtained descriptive data. All of the participants provided a written informed consent prior to testing and completed an injury history form. The athletes reported no orthopedic injury in the trunk, or lower and upper extremities over the last 6 months.

All badminton athletes performed 10-15 minutes of warm-up before joining any of the athletic testing stations. Balance, power, speed, and agility are the 4 main components in badminton and most sports. The examiner explained the testing procedure and the proper technique to perform the tests. The athletes were given a practice trial for each test to understand how to perform the test correctly. Following the practice trial and before the first recorded performance, a 4-minute rest period was given to the participants. Athletes completed each testing procedure for 3 times. All tests were performed in a random order, except for the core endurance tests, due to the fatiguing nature of those [12]. Age, weight, and height were recorded prior to session one.

The performance tests consisted of $\mathrm{Y}$ balance, vertical jump, $20 \mathrm{~m}$ sprint, agility, and single-leg triple crossover hop test (Figure 1). To assess the dynamic balance of athletes, Y balance test was used. Moreover, to normalize excursion distances, leg length test was employed. Reach directions were measured by fixing 3 tape measures to the floor, one in an anterior direction and two (posteromedial, posterolateral) aligned at 135 to the anterior direction. Dominant leg was used to assess reaching distance as far as possible in each of the 3 directions $[16,17]$.

The vertical jump test was performed to assess power. The athletes were requested to jump as high as possible; then, they were given one trial practice to perform the technique. If the athlete performed the procedure correctly, the score was recorded [18]. To measure the distance of hop test, a tape measure with approximately 6 meters of length was fixed to the ground. In the single-leg triple crossover hop test, the athletes were asked to perform 3 crossover hops on one leg. The athletes were also requested to control and hold the landing of the third hop for $3 \mathrm{~s}$. The final score of the single-leg triple crossover hop test was equal to the sum of the distance of the 3 hops [19].

The $20 \mathrm{~m}$ sprint test was applied to measure the speed. The athlete needed to accelerate quickly to top speed to cover the course as fast as possible. When the athlete crossed the finish line, the test was terminated and timing was recorded via a digital stopwatch [20]. To assess core endurance, the protocol established by McGill was used. In this protocol which consists of trunk flexor, trunk extensor, and bilateral side bridge tests (Figure 2), the athlete holds a static position for as long as possible [21].

A digital stopwatch was used to measure the time duration (in seconds) that the participants were able to hold each static position. The athletes laid on their side with their legs extended on a table for performing the side bridge test (left and right sides, individually), resting on their forearm, then they were asked to lift their hip off the table. The uninvolved arm was held across the chest with the hand placed on the opposite shoulder. The test was terminated when the straight body position could no longer be maintained. In the trunk flexor test, athletes were seated with their back resting against a wedge and maintained a $60^{\circ}$ flexion horizontally on the table.

Both knees and hips joints were flexed $90^{\circ}$, the arms were folded across the chest and the feet were stabilized by the researcher. The examiner pulled back the wedge for approximately $10 \mathrm{~cm}$; then, the athlete held the isometric posture of torso as long as possible. If any parts of the athlete's back touched the wedge, failure was determined. For performing the trunk extensor test, the athlete lied in a prone position on a table and upper body was cantilevered out over the end of the table. Athlete main- 
tained a horizontal body position and the arms were held across the chest while lower extremities were stabilized. The test was terminated when the upper body dropped below the horizontal position [21].

\section{Results}

After ensuring the normality of obtained data, multiple bivariate correlations represented by Pearson's correlation coefficients, were conducted to examine the relationship between core endurance and performance. Descriptive statistics were performed for all data. The data were analyzed by SPSS. The significance level was set at $\mathrm{P}<0.05$. A number of significant correlations were identified between core endurance and performance measures. The Mean \pm SD scores of endurance and performance variables are listed in Table 2. Correlations between core endurance variables and core endurance, as well as performance variable correlations are listed in Tables 3 and 4. Figure 3 shows the linear and quadratic regressions of total core endurance and total $\mathrm{Y}$ balance test, as well as linear and quadratic regressions of total core endurance and triple crossover hop test.

\section{Discussion}

Investigating the effect of core stability exercises on performance revealed that this exercise could significantly improve dynamic balance [22-25]. Sandrey and Mitzel (2013) suggested that a 6-week core stability training program significantly improved dynamic balance in high school track and field athletes [22]. Ibrahim Hassan also demonstrated that an 8-week core stability training program significantly improved the dynamic balance and performance level of smash stroke in young badminton players [24]. In addition, Rajiv Sighamoney et al. indicated that core stability exercises significantly increased $(\mathrm{P}=0.02)$ dynamic balance and agility among badminton players [25]. Therefore, balance and core stability may be correlated in badminton.

We investigated the relationship between core endurance and performance in professional young female badminton athletes. The obtained results indicated significant correlations between core endurance and dynamic balance $(\mathrm{r}=0.52, \mathrm{P}=0.04)$, as well as triple crossover hop $(\mathrm{r}=0.63, \mathrm{P}=0.01)$. In addition, badminton is a non-contact sport and most of the lower extremity injuries in this sport occur due to the loss of balance. The achieved results revealed significant correlations between core endurance and balance $(\mathrm{P}=0.04)$. Thus, it seems that by improving core muscles endurance, young badminton players can prevent the majority of non-contact lower extremity injuries that occur due to the loss of balance [26].

Improving core muscle endurance cannot prevent upper extremity injuries in badminton players. This is because there are no significant differences in core stability (or balance) between athletes with and without upper extremity injury [27]. For this reason, lower extremity examinations (e.g. Y balance test) were used to assess performance in the present study. Furthermore, because of the significant correlation between core endurance and triple crossover hop, badminton players can prevent ACL injury by improving their core muscle endurance. When badminton players jump and land in the lateral direction, knee valgus movement is larger and the risk of knee injury is higher [28].

Improving core stability could lead to smaller displacement in the mediolateral center of pressure and center of mass. By Improving core endurance/stability, the motion at the level of the trunk and hip is controlled and significantly improves balance [29]. Moreover, improving core muscles, like other skeletal muscles, results in enhancing the ability of neuromuscular system to stabilize contractions in response to gravity and momentum and leads to improved synchronization of motor units [30]. Dynamic balance is the ability of the body to maintain position after disturbances [31, 32] Having a stable spinal body posture can improve neuromuscular system ability to maintain position and dynamic balance control. In other words, a weak core or a defect in controlling the neuromuscular system can lead to the loss of dynamic balance [31, 32].

Overall, our obtained results suggested significant correlations between core endurance and balance; however, we found no significant relationships between core endurance and other performance variables (such as agility, sprint, and power). Core stability is a complicated concept that relates to different components, including endurance, strength, flexibility, motor control, and function [33].

Table 1. Descriptive characteristics of badminton athletes (Mean \pm SD)

\begin{tabular}{ccccc}
\hline Background (yr) & Age (yr) & Height (cm) & Weight (kg) & BMI (kg/m²) \\
\hline $7.0 \pm 1.6$ & $14.9 \pm 1.2$ & $163.0 \pm 4.5$ & $57.8 \pm 4.3$ \\
\hline
\end{tabular}




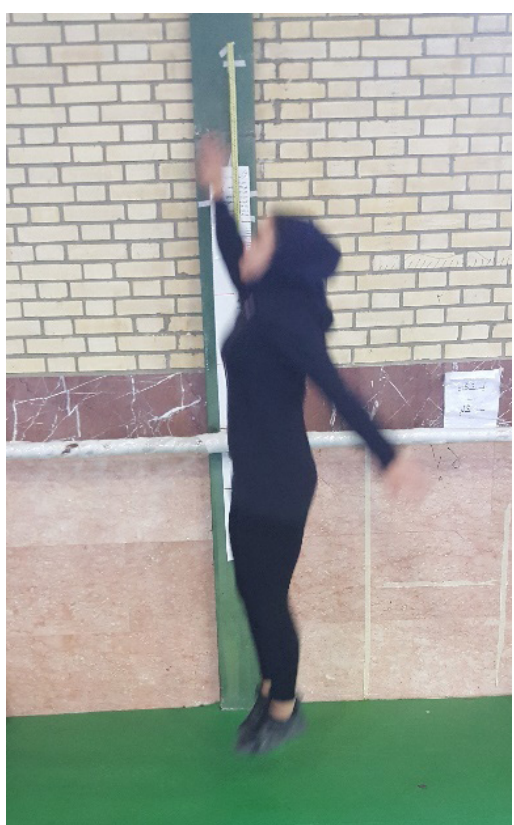

D

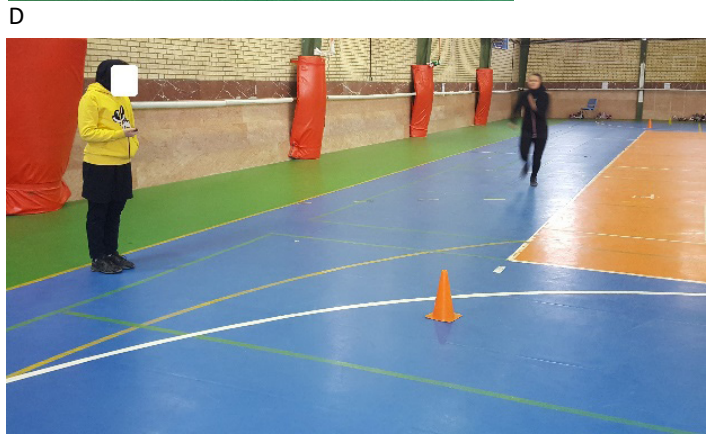

Figure 1. Balance and athletic performance test
B

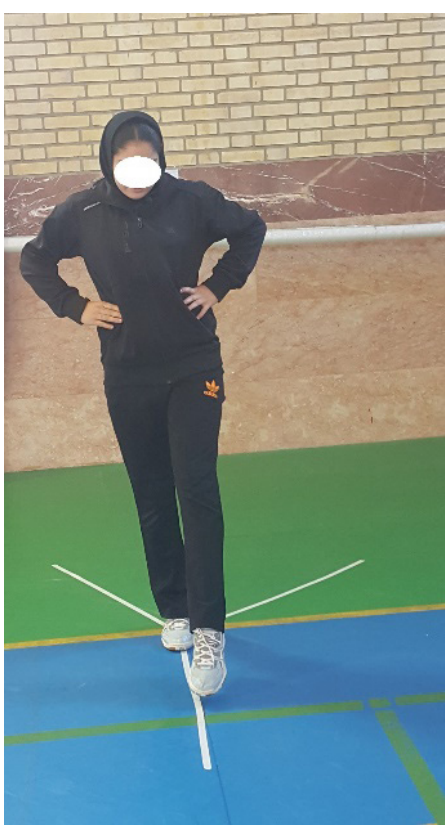

E
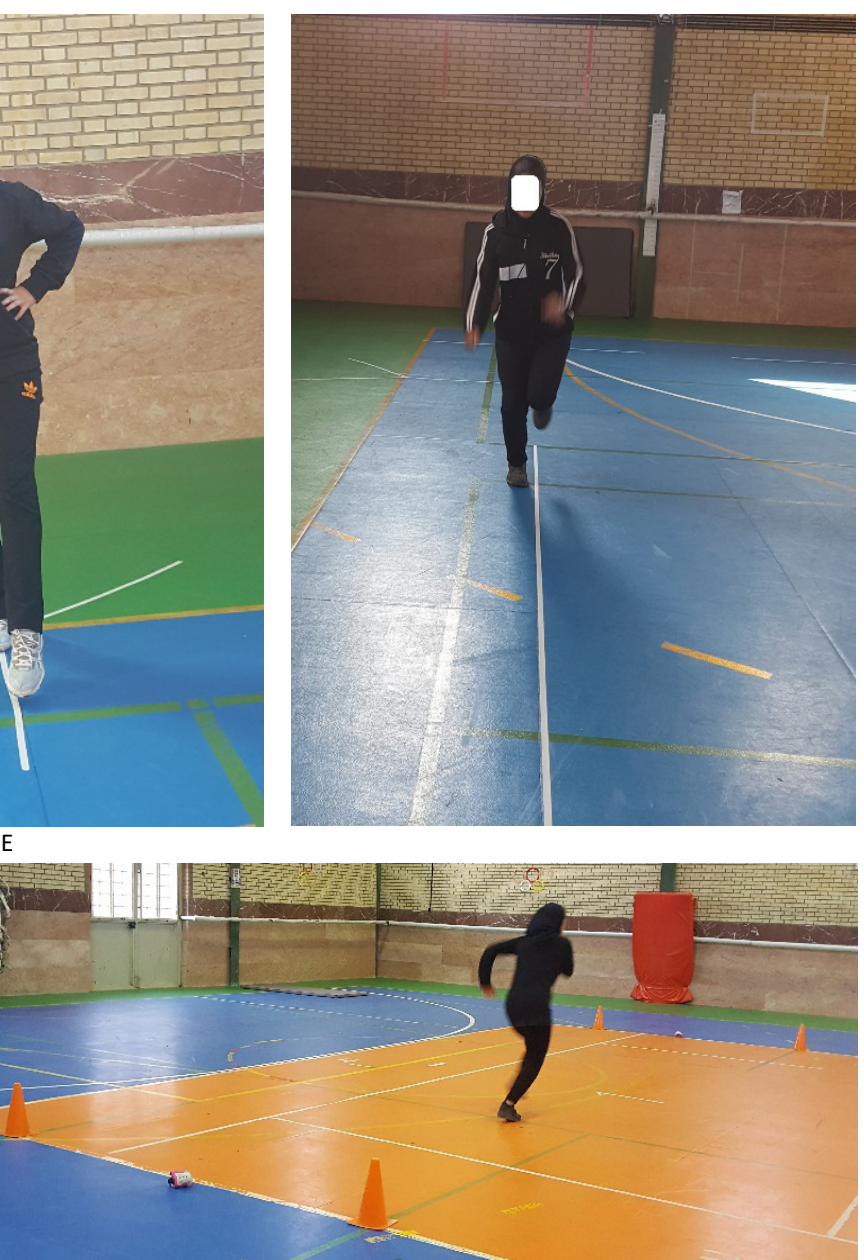

PHYSICAL TREA $\$$ MENTS

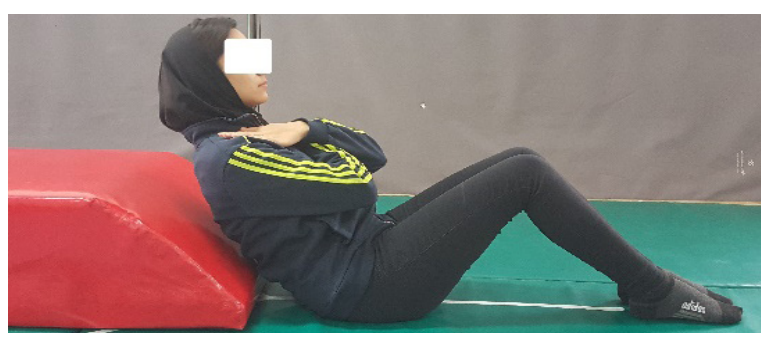

C

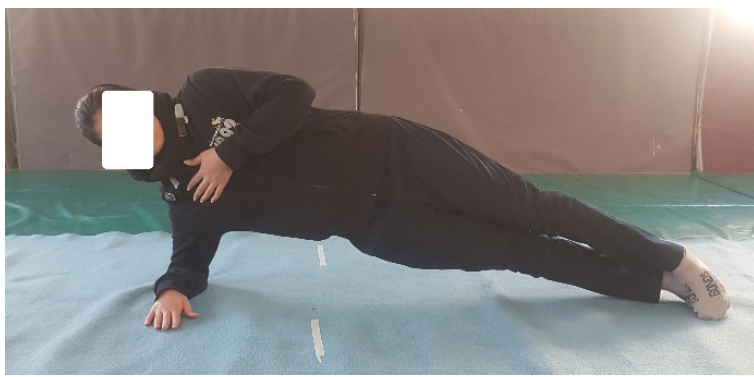

Figure 2. Core endurance test

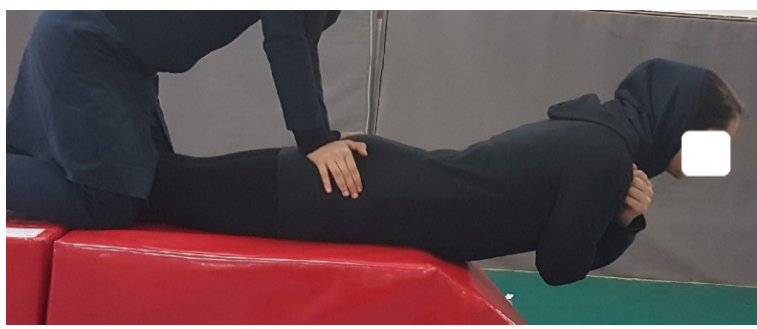

C

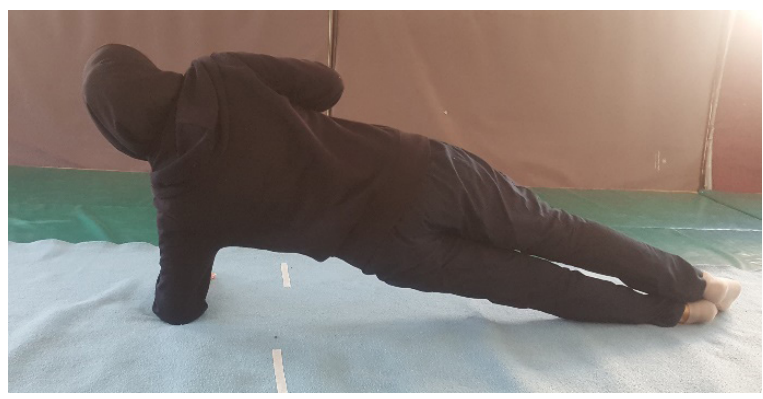

(A) Core endurance tests of trunk flexor, (B) trunk extensor, (C) and bilateral side bridge 
Table 2. Core endurance and performance variables (Mean \pm SD)

\begin{tabular}{|c|c|c|c|}
\hline \multicolumn{2}{|c|}{ Performance Test } & \multicolumn{2}{|c|}{ Core Endurance } \\
\hline Triple crossover hop test $(\mathrm{cm})$ & $497.3 \pm 58.9$ & Total core & $332.0 \pm 84.6$ \\
\hline $4 \times 9(s)$ & $10.9 \pm 0.6$ & Left side bridge & $50.3 \pm 17.5$ \\
\hline $20 \mathrm{~m}$ sprint test (s) & $3.8 \pm 0.7$ & Right side bridge & $46.9 \pm 18.3$ \\
\hline Vertical jump test (cm) & $32.7 \pm 4.2$ & Trunk extensor & $97.3 \pm 23.9$ \\
\hline Total Y balance test $(\mathrm{cm})$ & $99.9 \pm 9.2$ & Trunk flexor & $137.4 \pm 44.3$ \\
\hline Anterior $\mathrm{Y}$ balance test $(\mathrm{cm})$ & $82.1 \pm 8.1$ & - & - \\
\hline Posterolateral Y balance test $(\mathrm{cm})$ & $93.4 \pm 58.9$ & - & - \\
\hline Posteromedial Y balance test $(\mathrm{cm})$ & $84.3 \pm 10.4$ & - & - \\
\hline
\end{tabular}

PHYSICAL TREA $\ M E N T S$

Table 3. Correlations between core endurance variables

\begin{tabular}{|c|c|c|c|c|}
\hline Core Endurance Test & Left Side Bridge & Right Side Bridge & Trunk Extensor & Trunk Flexor \\
\hline Left side bridge & 1 & - & - & - \\
\hline Right side bridge & $0.93 * *$ & 1 & - & - \\
\hline Trunk extensor & $0.64^{* *}$ & $0.63^{* *}$ & 1 & - \\
\hline Trunk flexor & $0.63^{* *}$ & $0.57 *$ & 0.19 & 1 \\
\hline
\end{tabular}

Thirsty-five tests used to assess the core stability (core endurance, flexibility, strength, neuromuscular control, and functional tests) were examined. The obtained data suggested that core endurance test group is the most reliable examination method for measuring the core stability, followed by the flexibility, strength, neuromuscular control, and functional tests, respectively [33]. For this reason, lower extremity tests (e.g. Y balance test) were used to assess performance in the present study.

To assess core endurance, McGill's tests were used in this study. These tests were designed to measure muscle

A

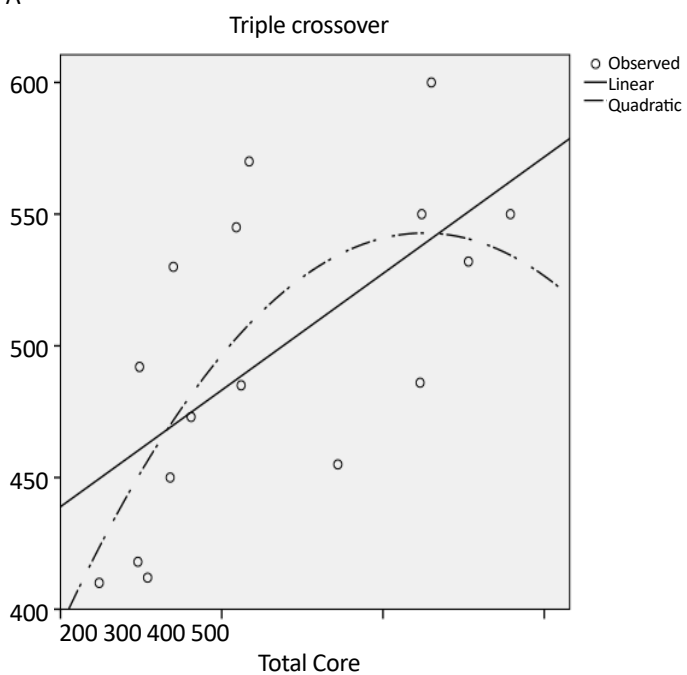

B

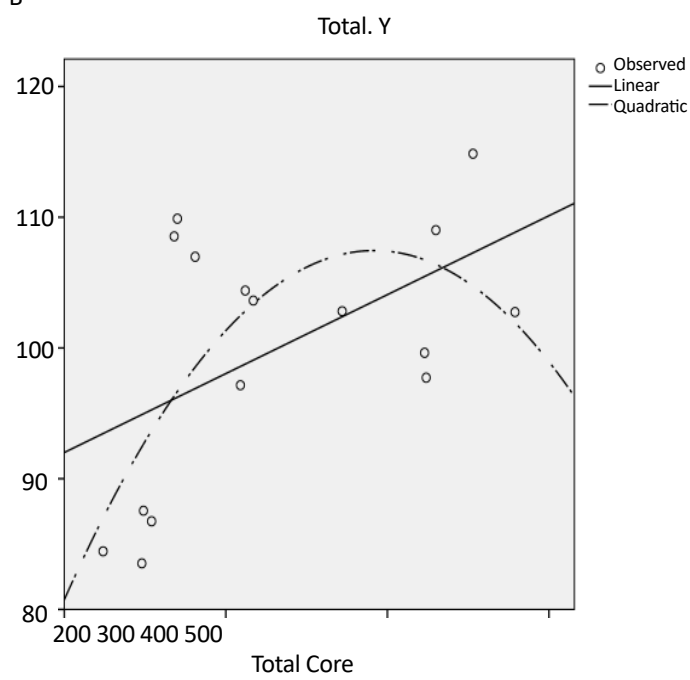

Figure 3. The correlation between core endurance and performance test

PHYSICAL TREA $\ M E N T S$

(A) The regressions of core endurance and total $Y$ balance test, and (B) the regressions of core endurance and triple crossover hop 
Table 4. Correlations between core endurance and performance variables

\begin{tabular}{|c|c|c|c|c|c|c|c|c|c|c|}
\hline \multirow{2}{*}{ Core Endurance Test } & \multicolumn{2}{|c|}{ Total Y Balance Test } & \multicolumn{2}{|c|}{ Vertical Jump Test } & \multicolumn{2}{|c|}{$20 \mathrm{~m}$ Sprint Test } & \multicolumn{2}{|c|}{$4 \times 9$ Agility Test } & \multicolumn{2}{|c|}{ Triple Crossover Tes } \\
\hline & $r$ & Sign & $r$ & Sign & $r$ & Sig. & $\mathbf{r}$ & Sign & $r$ & Sign \\
\hline Total core & $0.52 *$ & 0.04 & 0.07 & 0.78 & -0.27 & 0.30 & -0.20 & 0.44 & $0.63 * *$ & 0.01 \\
\hline Left bridge & $0.52^{*}$ & 0.04 & 0.31 & 0.24 & -0.26 & 0.32 & -0.28 & 0.30 & $0.73^{* *}$ & 0.01 \\
\hline Right bridge & $0.61^{*}$ & 0.02 & 0.26 & 0.32 & -0.20 & 0.45 & -0.24 & 0.36 & $0.76 * *$ & 0.01 \\
\hline Trunk extensor & 0.14 & 0.60 & 0.17 & 0.51 & -0.06 & 0.81 & -0.36 & 0.16 & $0.50 *$ & 0.05 \\
\hline Trunk flexor & 0.46 & 0.07 & -0.18 & 0.49 & -0.29 & 0.26 & 0.01 & 0.96 & 0.33 & 0.20 \\
\hline
\end{tabular}

${ }^{*} \mathrm{P}<0.05 ;{ }^{* * \mathrm{P}<0.01}$

PHYSICAL TREA TMENTS

core endurance. The weak or insignificant correlations between the core stability and other performance tests (such as agility, sprint, and power) might be due to the specificity of tests. The performance tests applied in this study were quick and explosive lasting less than $10 \mathrm{~s}$ that involved primarily fast twitch muscle fibers; however, the McGill's core endurance tests mostly focus on slow twitch muscle fibers. In-line with the results of Sharrock et al. another possible reason is that core endurance does not significantly contribute to athletic performance [13].

The obtained results indicated that triple crossover hop and dynamic balance are significantly correlated with core endurance. The role of core endurance in performance, as well as injuries prevention in badminton is important. Thus, further research is required to determine a definitive answer on the nature of this relationship. The obtained results could be helpful for coaches, players, and athletic trainers who are in contact with professional female badminton athletes.

\section{Ethical Considerations}

\section{Compliance with ethical guidelines}

All athletes read and signed a written informed consent before testing and completed a detailed injury history form. The study participants were informed about the purpose of research and its implementation stages; they were also assured about the confidentiality of their information. Moreover, they were allowed to discontinue participation in the study as desired. Finally, if desired, the results of the research would be available to them.

\section{Funding}

This research did not receive any specific grant from funding agencies in the public, commercial, or not-forprofit sectors.

\section{Authors' contributions}

Conceptualization, Methodology, Investigation, Resources, Data gathering, Writing - Original draft, Preparation, Project administration: Hemn Mohammadi; and Statistical Analysis, Language refinement and Editing: Jalil Fathi.

\section{Conflict of interest}

The authors declared no conflict of interest.

\section{Acknowledgments}

The authors appreciate all of the young national female badminton players, coaches, trainer, and staff of Physical Education and Sports Sciences Laboratory of the Shahrood University of Technology.

\section{References}

[1] Nhan DT, Klyce W, Lee RJ. Epidemiological patterns of alternative racquet-sport injuries in the United States, 19972016. Orthopaedic Journal of Sports Medicine. 2018; 6(7):1-7. [DOI:10.1177/2325967118786237] [PMID] [PMCID]

[2] Kuntze G, Mansfield N, Sellers W. A biomechanical analysis of common lunge tasks in badminton. Journal of Sports Sciences. 2010; 28(2):183-91. [DOI:10.1080/02640410903428533] [PMID]

[3] Kimura Y, Tsuda E, Hiraga Y, Maeda S, Sasaki S, Sasaki E, et al. Trunk motion and muscular strength affect knee valgus moment during single-leg landing after overhead stroke in badminton. British Journal of Sports Medicine. 2014; 48(7):620. [DOI:10.1136/bjsports-2014-093494.163]

[4] Tiwari LM, Rai V, Srinet S. Relationship of selected motor fitness components with the performance of badminton player. Asian Journal of Exercise and Sports Science. 2011; 5(1):88-91. 
[5] Reeves J, Hume P, Gianotti S, Wilson B, Ikeda E. A retrospective review from 2006 to 2011 of lower extremity injuries in badminton in New Zealand. Sports. 2015; 3(2):77-86. [DOI:10.3390/sports3020077]

[6] Behm DG, Leonard AM, Young WB, Bonsey WA, MacKinnon SN. Trunk muscle electromyographic activity with unstable and unilateral exercises. The Journal of Strength and Conditioning Research. 2005; 19(1):193-201. [DOI:10.1519/15334287(2005)192.0.CO;2] [PMID]

[7] Cissik JM. Programming abdominal training, Part II. Strength \& Conditioning Journal. 2002; 24(2):9-12. [DOI:10.1519/15334295(2002)0242.0.CO;2]

[8] Tse MA, McManus AM, Masters RS. Development and validation of a core endurance intervention program: Implications for performance in college-age rowers. The Journal of Strength \& Conditioning Research. 2005; 19(3):547-52. [DOI:10.1519/15424.1] [PMID]

[9] Stanton R, Reaburn PR, Humphries B. The effect of shortterm Swiss ball training on core stability and running economy. The Journal of Strength \& Conditioning Research. 2004; 18(3):522-8. [DOI:10.1519/00124278-200408000-00023]

[10] Scibek JS. The effect of core stabilization training on functional performance in swimming [PhD. dissertation]. Chapel Hill, North Carolina: University of North Carolina at Chapel Hill; 1999.

[11] Ozmen T, Aydogmus M. Effect of core strength training on dynamic balance and agility in adolescent badminton players. Journal of Bodywork and Movement Therapies. 2016; 20(3):565-70. [DOI:10.1016/j.jbmt.2015.12.006] [PMID]

[12] Nesser TW, Huxel KC, Tincher JL, Okada T. The relationship between core stability and performance in division I football players. The Journal of Strength \& Conditioning Research. 2008; 22(6):1750-4. [DOI:10.1519/JSC.0b013e3181874564] [PMID]

[13] Sharrock C, Cropper J, Mostad J, Johnson M, Malone T. A pilot study of core stability and athletic performance: Is there a relationship. International Journal of Sports Physical Therapy. 2011; 6(2):63-74. [PMID] [PMCID]

[14] Liemohn WP, Baumgartner TA, Gagnon LH. Measuring core stability. The Journal of Strength and Conditioning Research. 2005; 19(3):583-6. [DOI:10.1519/15334287(2005)19[583:MCS]2.0.CO;2] [PMID]

[15] Sahrmann S, Azevedo DC, Dillen LV .Treatment and diagnosis of movement impairment syndromes. Brazilian Journal of Physical Therapy. 2017; 21(6):391-9. [DOI:10.1016/j. bjpt.2017.08.001] [PMID] [PMCID]

[16] Gribble PA, Kelly SE, Refshauge KM, Hiller CE. Interrater reliability of the star excursion balance test. Journal of Athletic Training. 2013; 48(5):621-6. [DOI:10.4085/1062-605048.3.03] [PMID] [PMCID]

[17] Munro AG, Herrington LC. Between-session reliability of the star excursion balance test. Physical Therapy in Sport. 2010; 11(4):128-32. [DOI:10.1016/j.ptsp.2010.07.002] [PMID]

[18] Son C, Stewart A, Ward J, Farrar K. Lower body strengthtraining versus proprioceptive exercises on vertical jump capacity: A feasibility study. Journal of Chiropractic Medicine. 2018; 17(1):7-15. [DOI:10.1016/j.jcm.2017.10.007] [PMID] [PMCID]
[19] Mohammadi H, Daneshmandi H, Alizadeh MH, Shamsimajlan A. [Screening tests for neuromuscular imbalance that affecting the non-contact ACL injury- A review article (Persian)]. Scientific Journal of Kurdistan University of Medical Sciences 2015; 20(2):85-105.

[20] Delextrat A, Cohen D. Strength, power, speed, and agility of women basketball players according to playing position. The Journal of Strength and Conditioning Research. 2009; 23(7):1974-81. [DOI:10.1519/JSC.0b013e3181b86a7e] [PMID]

[21] McGill S. Low back disorders. Evidence-based prevention and rehabilitation. Champaign: Human Kinetics; 2014.

[22] Sandrey MA, Mitzel JG. Improvement in dynamic balance and core endurance after a 6-week core-stability-training program in high school track and field athletes. Journal of Sport Rehabilitation. 2013; 22 (4):264-71. [DOI:10.1123/ jsr.22.4.264]

[23] Granacher U, Schellbach J, Klein, K, et.al. Effects of core strength training using stable versus unstable surfaces on physical fitness in adolescents: a randomized controlled trial. BMC Sports Science, Medicine and Rehabilitation. 2014; 15:6(1):40. [DOI:10.1186/2052-1847-6-40] [PMID] [PMCID]

[24] Hassan IH. The effect of core stability training on dynamic balance and smash stroke performance in badminton players. International Journal of Sports Science and Physical Education. 2017; 2(3):44-52. [DOI:10.11648/j.ijsspe.20170203.12]

[25] Sighamoney R, Kad R, Yeole UL. Effect of core strengthening on dynamic balance and agility in badminton players. International Journal of Physical Education, Sports and Health. 2018; 5(1):86-8.

[26] Lin Kang A, Ramalingam, V. (2018). Risk factors for lower extremity injuries in young badminton players. Scientia Medica. 2018; 28(2):8939. [DOI:10.15448 /19806108.2018.2.28939]

[27] Pontillo M, Silfies S, Butowicz CM, Thigpen C, Sennett B, Ebaugh D. Comparison of core stability and balance in athletes with and without shoulder injuries. International Journal of Sports Physical Therapy. 2018; 13(6):1015-23. [DOI:10.26603/ijspt20181015] [PMID] [PMCID]

[28] Shuhei N, Urabe Y, Tekeuchi T, Sasadai J, Maeda N. P 179analysis of dynamic knee motion during lateral and posterolateral jump landing in female badminton players. Gait \& Posture. 2018; 65:537-9. [DOI:10.1016/j.gaitpost.2018.07.099]

[29] Chevidikunnan MF, Al Saif A, Gaowgzeh RA, Mamdouh KA. Effectiveness of core muscle strengthening for improving pain and dynamic balance among female patients with patellofemoral pain syndrome. Journal of Physical Therapy Science. 2016; 28(5):1518-23. [DOI:10.1589/jpts.28.1518] [PMID] [PMCID]

[30] Cosio-Lima LM, Reynolds KL, Winter C, Paolone V, Jones MT. Effects of physioball and conventional floor exercises on early phase adaptations in back and abdominal core stability and balance in women. The Journal of Strength \& Conditioning Research. 2003; 17(4):721-5. [DOI:10.1519/00124278200311000-00016]

[31] Zazulak BT, Hewett TE, Reeves NP, Goldberg B, Cholewicki J. Deficits in neuromuscular control of the trunk predict knee injury risk: Prospective biomechanical-epidemiologic study. The American Journal of Sports Medicine. 2007; 35(7):1123-30. [DOI:10.1177/0363546507301585] [PMID] 
[32] dos Anjos Rabelo ND, Lima B, dos Reis AC, Bley AS, Yi LC, Fukuda TY, et al. Neuromuscular training and muscle strengthening in patients with patellofemoral pain syndrome: A protocol of randomized controlled trial. BMC Musculoskeletal Disorders. 2014; 15:157. [DOI:10.1186/14712474-15-157] [PMID] [PMCID]

[33] Andy Waldhelm, Li Li. Endurance tests are the most reliable core stability related measurements. Journal of Sport and Health Science. 2012; 1(2):121-28. [DOI:10.1016/j. jshs.2012.07.007] 
This Page Intentionally Left Blank 